\title{
Eddy correlation flux measurements: The sediment surface area that contributes to the flux
}

\section{Peter Berg 1}

Department of Environmental Sciences, University of Virginia, 291 McCormick Road, P.O. Box 400123, Charlottesville, Virginia 22904-4123

\section{Hans Røy}

Max Planck Institute for Marine Microbiology, Celsiusstrasse 1, 28359 Bremen, Germany

\section{Patricia L. Wiberg}

Department of Environmental Sciences, University of Virginia, 291 McCormick Road, P.O. Box 400123, Charlottesville, Virginia 22904-4123

\begin{abstract}
We investigated the size and shape of the area on the sediment surface, the so-called footprint, that contributes to the flux in subaqueous eddy correlation measurements. Tracer tracking simulations were performed for a dissolved conservative tracer released from the sediment surface into a current-driven flow not affected by density stratifications and surface waves. Simulations revealed that the footprint length $(l)$ can be calculated as $l=$ $-2.783-158.7 h+159.2 h^{2}-120.8 h \log \left(z_{0}\right)$ (all units in $\mathrm{m}$ ) for eddy correlation measurements heights $(h)$ between 0.05 and $0.3 \mathrm{~m}$ above the sediment surface and for sediment surface roughness parameter $\left(z_{0}\right)$ values between 7.04 $\times 10^{-6}$ and $0.01 \mathrm{~m}$. The upstream distance $\left(x_{\max }\right)$ to the location that contributes the strongest flux signal can likewise be estimated as $x_{\max }=-0.09888-11.53 h+10.25 h^{2}-6.650 h \log \left(z_{0}\right)$. Because vertical turbulent mixing scales with mean current velocity, $l$ and $x_{\max }$ are independent of current velocity. The footprint width $(w)$ can be calculated as $w=6.531 h$. These expressions were developed for water depths $(H)$ of $H>27 h$. In the depth interval $6.7 \mathrm{~h}<H<27 \mathrm{~h}, l$ can be calculated by multiplying the length, as given above, by the factor $1+8.347 \exp (-0.2453$ $H / h$ ), whereas $x_{\max }$ is independent of $H$. For $H<6.7 h$, the tracer transfer rate over the air-water interface controls the size and shape of the footprint. All expressions are valid for isotropic turbulence, but as a first-order estimate, the expressions for $l$ and $x_{\max }$ also hold for anisotropic conditions. In contrast, $w$ scales with $\sqrt{E_{y} / E_{z}}$, where $E_{y}$ and $E_{z}$ are the transverse and the vertical eddy diffusivity, respectively. Finally, we describe how site-specific values of $z_{0}$ and levels of anisotropy in a turbulent near-bottom flow can be extracted directly from eddy correlation measurements.
\end{abstract}

For decades the eddy correlation technique has been used to determine land-atmosphere and sea-atmosphere exchanges of energy, water vapor, and gases (e.g., Swinbank 1951; Baldocchi et al. 1988; Wyngaard 1989). Recently, the technique has also been adapted for dissolved species in the aquatic environment by Berg et al. (2003) and Kuwae et al. (2006), who determined sediment-water fluxes of $\mathrm{O}_{2}$ from high-resolution measurements of vertical velocity and $\mathrm{O}_{2}$ concentration. The velocity was recorded with an acoustic Doppler velocimeter (Nortek AS, or SonTek/YSI), and the $\mathrm{O}_{2}$ concentration was measured with a fast Clark-type microelectrode (Revsbech 1989). Berg et al. (2003) typically measured these two variables $0.15 \mathrm{~m}$ above the sediment surface at $25 \mathrm{~Hz}$, and extracted $\mathrm{O}_{2}$ exchange from 10-min-long time series. Sediment-water

${ }^{1}$ Corresponding author (pb8n@virginia.edu).

\section{Acknowledgments}

We thank two anonymous reviewers for their constructive comments. Also, we greatly appreciate the help and advice we have received from Gaby Katul on adapting findings from the atmospheric boundary layer research in our work. This study was cosponsored by the National Science Foundation (OCE-0221259) and the Max Planck Society. fluxes of species other than $\mathrm{O}_{2}$ can also be determined through eddy correlation measurements if the appropriate chemical sensors are available.

The eddy correlation technique has significant advantages over traditional methods such as laboratory incubations of sediment cores and in situ chamber incubations. For example, measurements are made under true in situ conditions, i.e., without disturbing the sediment, and under natural light and hydrodynamic conditions. For that reason, the technique is superior to traditional methods in most applications and can also be used specifically for bioirrigated or highly permeable sandy sediments where traditional methods fail.

Given the novelty of the eddy correlation technique in the aquatic environment, many aspects associated with the approach need to be investigated. In this paper, we focus on the sediment surface area that contributes to the flux determined with the technique. This area is usually referred to as the source-weight function or simply the footprint in the atmospheric boundary layer literature. Here, we have adopted the latter term. The field conditions we consider include a broad variety of water depths and sediment surface roughnesses exposed to different unidirectional mean current velocities. We have limited our study to field 
conditions with negligible influence from surface waves and insignificant water-column density stratification.

Intuitively, one can predict that the footprint has a long oval shape and is located upstream from the point where the vertical velocity and the species concentration are measured (Fig. 1A). In order to study the size and shape of the footprint in a systematic way, an exact definition of this area is required. Here, we have adopted the definition from the atmospheric boundary layer research as the smallest area on the sediment surface that contributes $90 \%$ of the flux registered at the measuring point (e.g., Leclerc and Thurtell 1990; Schuepp et al. 1990; Schmid 2002). It would be obvious to apply the results from these studies directly to the aquatic environment. However, this is generally not possible because the water depth, as we show here, exhibits a major control on the footprint. Given the difficulties associated with examining the footprint experimentally, we have chosen a theoretical tracer tracking approach based on detailed three-dimensional (3D) mathematical modeling of the transport and dispersion of a dissolved conservative tracer in a turbulent near-bottom flow.

\section{Methods}

Mathematical formulation-The 3D mathematical formulation of solute transport in a turbulent flow used in our modeling is

$$
\begin{aligned}
\frac{\partial \bar{C}}{\partial t}= & \frac{\partial}{\partial x}\left(\left(D+E_{x}\right) \frac{\partial \bar{C}}{\partial x}\right)+\frac{\partial}{\partial y}\left(\left(D+E_{y}\right) \frac{\partial \bar{C}}{\partial y}\right) \\
& +\frac{\partial}{\partial z}\left(\left(D+E_{z}\right) \frac{\partial \bar{C}}{\partial z}\right)-\overline{u_{x}} \frac{\partial \bar{C}}{\partial x},
\end{aligned}
$$

where $t$ is time; $x, y$, and $z$ are directions in a Cartesian coordinate system (Fig. 1A); $\bar{C}$ is time-averaged species concentration; $\overline{u_{x}}$ is time-averaged current velocity parallel to the $x$ axis; $D$ is molecular diffusivity; and $E_{x}, E_{y}$, and $E_{z}$ are the turbulent eddy diffusivities in the $x, y$, and $z$ directions. It should be noted that due to averaging and the choice of coordinate system (Fig. 1A), Eq. 1 only contains an advective term in the $x$ direction. For further details on this time averaging and the derivation of Eq. 1 from the general 3D mass-conservation equation in a turbulent flow, see, for example, Stanišić (1985) or Boudreau (1997).

For the vertical eddy diffusivity $\left(E_{z}\right)$ in Eq. 1, we adopted the following empirical relationship (Rattray and Mitsuda, 1974; Wiberg and Smith, 1991; Boudreau, 2001) and assumed the turbulence to be isotropic:

$$
\begin{aligned}
& E_{z}=\kappa u_{*} z \quad \text { for } \quad z \leq \frac{H}{15.6 \kappa} \\
& E_{z}=\frac{u_{*} H}{15.6} \quad \text { for } \quad z>\frac{H}{15.6 \kappa}, \\
& E_{x}=E_{y}=E_{z}
\end{aligned}
$$

where $\kappa$ is von Karman's constant $(0.41), u_{*}$ is friction velocity, $z$ is height above the sediment surface, and $H$ is water depth. The assumption of the isotropic nature of the turbulence in the near-bottom flow, the expression for $E_{z}$, and their effects on the footprint are examined in detail below.

Finally, the variation of the mean current velocity $\left(\overline{\mathrm{u}_{x}}\right)$ as a function of $z$ is described as

$$
\begin{aligned}
& \overline{u_{x}}=0 \quad \text { for } \quad z \leq z_{0} \\
& \overline{u_{x}}=\frac{u_{*}}{\kappa} \ln \frac{z}{z_{0}} \quad \text { for } z_{0}<z \leq \frac{H}{15.6 \kappa}, \\
& \overline{u_{x}}=\frac{15.6 u_{*}}{H}\left(z-\frac{z^{2}}{2 H}\right)+\frac{u_{*}}{\kappa}\left(\ln \frac{H}{15.6 \kappa z_{0}}-1+\frac{1}{31.2 \kappa}\right) \\
& \text { for } z>\frac{H}{15.6 \kappa}
\end{aligned}
$$

where $z_{0}$ is the sediment surface roughness parameter. The classical log profile in the interval $z_{0}<z \leq H /(15.6 \kappa)$ can be derived from Eq. 2 and $\tau_{z x}=\rho K_{z} d \overline{u_{x}} / d z$, assuming that shear stress $\left(\tau_{z x}\right)$ is constant and equal to the shear stress at the bottom $\left(\tau_{b}=\rho u_{*}^{2}\right)$ in this layer and that $E_{z}=K_{z}$, where $K_{z}$ is the eddy viscosity and $\rho$ is the density. The parabolic profile in the interval $z>H /(15.6 \kappa)$ is also consistent with Eq. 2 as it can be derived assuming a linear increase in shear stress with depth from a value of zero at the air-water interface. Because velocities at values of $z \leq z_{0}$ are very small and contribute negligibly to tracer transport, we set $\overline{u_{x}}=0$ for $z \leq z_{0}$ in Eq. 3 .

Numerical solution-No universal analytical solution to Eq. 1 in combination with Eqs. 2 and 3 exists. For that reason, we solved Eq. 1 numerically. A steady-state solution of Eq. 1, with an adequately high-resolution discretization in the $x, y$, and $z$ directions, is often computationally demanding. Furthermore, a detailed analysis of the size and shape of the footprint demands numerous solutions to cover all field conditions of interest. For that reason, we developed a numerical scheme for solving Eq. 1 that requires minimal computation time. We used a control volume approach in this formulation (Patankar 1980), where each solution is produced as a transient simulation continued until steady state is reached. The minimal use of computation time was achieved in part by separating the full $3 \mathrm{D}$ solution into a series of two-dimensional (2D) solutions as follows.

In the direction of the mean current velocity ( $x$ direction; Fig. 1A), advection is much more important than molecular or turbulent eddy diffusion. This essentially means that any given point in the calculation domain is only influenced by conditions upstream of that point, and thus is independent of downstream conditions. For that reason, the full 3D transient solution at any time step can be produced efficiently as a series of $2 \mathrm{D}$ solutions in the $y-z$ plane (Fig. 1A), starting at the upstream boundary and successively moving in the downstream direction. This highly 


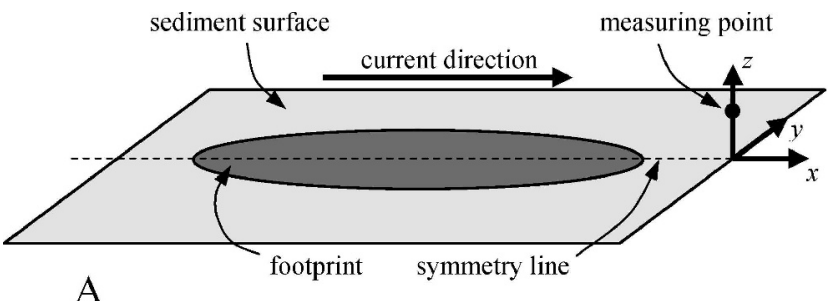

A

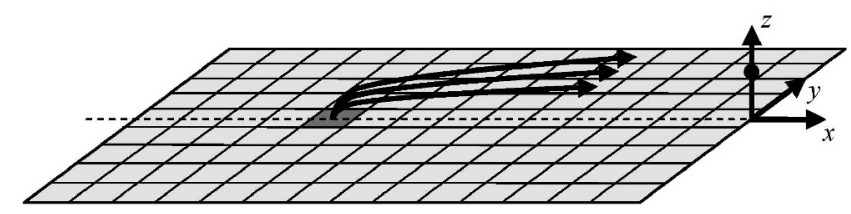

$\mathrm{B}$

Fig. 1. (A) Schematic illustration of the sediment surface, current direction, the measuring point where eddy correlation data are recorded, and the footprint. Symmetry exists around the $x-z$ plane; $y=0$. (B) Schematic illustration of the surface elements that result from projecting the control volume discretization onto the sediment surface. The downstream transport and dispersion of a dissolved conservative tracer, released at a constant rate from one surface element located on the symmetry line, is determined through the numerical steady-state solution of Eq. 1 in combination with Eqs. 2 and 3.

beneficial characteristic is formulated numerically by approximating the advective term in Eq. 1 with an upstream discrete approximation as $\left(\overline{u_{x}} \partial \bar{C} / \partial x\right)_{i} \sim \overline{u_{x i}}\left(\bar{C}_{i}-\bar{C}_{i-1}\right) / \Delta x$ for $\overline{u_{x}}>$ 0 (e.g., Patankar 1980).

At each time step, the 2D transient solutions for each $y-z$ plane is produced by the stable and efficient "implicit alternating direction method" (Douglas 1955; Peaceman and Rachford 1955; summarized by Carnahan et al. 1969). It should be noted that the diffusive term in Eq. 1 for the $x$ direction is not neglected in this scheme but is included using a simple explicit central difference approximation (e.g., Patankar 1980). To further minimize computation requirements, the finest control volume discretization is prescribed where the numerically largest second derivatives of $\bar{C}$ in Eq. 1 are expected. Also, because all solutions to Eq. 1 sought here exhibit symmetry around the $x-z$ plane, $y$ $=0$ (Fig. 1A), solutions are only computed for $y \geq 0$ and then mirrored around this plane. This reduces the computational effort by a further factor of two.

Mapping out the footprint-The size and shape of the footprint for a given water depth $(H)$, friction velocity $(u *)$, sediment surface roughness parameter $\left(z_{0}\right)$, and measuring height $(h)$ above the sediment surface are determined in a several-step process. The key element is a determination of the signal strength at the measuring point from a known flux released at different locations on the sediment surface. This information is extracted from one single steady-state tracer tracking simulation as follows.

The projection of the control volume discretization onto the sediment surface separates it into a series of rectangular elements (Fig. 1B). The downstream transport and dispersion of a conservative tracer released at a constant rate from one surface element located on the symmetry line is then determined by solving Eq. 1 in combination with Eqs. 2 and 3. A zero tracer release is imposed for all other surface elements. All other boundary conditions are outlined below. This single steady-state simulation reveals the tracer flux distribution through the entire $x-y$ plane at $z=$ $h$, which contains the measuring point (Fig. 1B). The distribution is then used to derive, for each individual surface element, the flux that is registered at the measuring point when the tracer is released from the surface element. This new distribution is then sorted in decreasing order, and a new variable is defined as the flux contributions multiplied by the surface element areas of their origin. Since the principle of superposition applies to solutions of Eq. 1, the new variable is summarized in the sorted order until the cumulative value has reached $90 \%$ of the imposed tracer released in the tracer tracking simulation. All of the surface elements accounted for in this sum together form the footprint. Due to the rectangular shape of the surface elements (Fig. 1B), the contour of the footprint is not a smooth curve. As a final step, a smooth contour is obtained simply through interpolation in both the $x$ and $y$ directions between all pairs of surface elements adjacent to the boundary of the footprint. This procedure uniquely defines the size and shape of the footprint as the smallest area on the sediment surface that contributes $90 \%$ of the flux registered at the measuring point for the chosen values of $H, u_{*}, z_{0}$, and $h$.

Initial and boundary conditions-A zero tracer concentration is used as the initial condition in the tracer tracking simulations. The boundary condition at the lower boundary, the sediment surface, is described above. At the upper boundary, the air-water interface, the tracer exchange $\left(J_{\text {air-water }}\right)$ is given by the following expression (e.g., Liss and Slater 1974; Marino and Howarth 1993; Borges et al. 2004),

$$
J_{\text {air-water }}=k \Delta \bar{C}_{\text {air-water }},
$$

where $k$ is the transfer coefficient, often referred to as the piston velocity, and $k \Delta \bar{C}_{\text {air-water }}$ is the concentration difference over the thin film on the water side of the interface through which the transport occurs by molecular diffusion. More sophisticated expressions exist for this exchange, but the one adopted here is the most widely known and used.

A zero flux is imposed at the upstream boundary as the result of the initial condition of zero concentration and in the absence of concentration gradients at this boundary. A zero concentration gradient is specified at the downstream boundary. This condition neglects any diffusive transport across the boundary, but as argued above, molecular and turbulent eddy diffusion are insignificant relative to advection in the $x$ direction. At the boundary $y=0$, symmetry in the solution is imposed. At the remaining boundary, perpendicular to the $y$ axis, a zero flux is imposed. 
Test of numerical solution - It is impossible to set up an experiment in a flume or in situ from which one can map out the $90 \%$ footprint. For that reason, we tested our numerical scheme under several simplified conditions for which analytical solutions exist. For example, neglecting the $x$ and $y$ directions and considering only steadystate conditions, Eq. 1 simplifies to $\partial\left(\left[D+E_{z}\right] \partial \bar{C} / \partial z\right) / \partial z$ $=0$, which, when combined with $E_{z}=\kappa u_{*} z$ (Eq. 2), can be solved analytically. The equivalent numerical solution was produced with a typical control volume discretization used in the tracer tracking simulations and gave the same result within $0.07 \%$. Similar tests were conducted for the $y$ and $x$ directions with the same result.

Furthermore, the tracer tracking simulations that produced the largest footprint (outlined below) were repeated with a calculation domain extended by a factor of two in all three directions. This larger calculation domain gave the same footprint, confirming that all boundary conditions were imposed at adequate distances from the tracer release in all simulations. Likewise, the simulation leading to the smallest footprint was repeated with a control volume discretization that was refined by a factor of two in all three directions. This finer spatial resolution also resulted in the same footprint, revealing that an adequately fine control volume discretization was used in all simulations. As a final test of our numerical procedure, we compared the length of a predicted footprint with simplified analytical solutions derived in the field of atmospheric boundary layer research. These comparisons are described below.

\section{Results and discussion}

Footprint characteristics - Some key characteristics of footprints and their dependencies are illustrated in Figs. 2 and 3. The oval-shaped footprint shown in Fig. 2A, some 70-m long and 2-m wide, was calculated for a water depth $(H)$ of $15 \mathrm{~m}$, a measuring height $(h)$ of $0.3 \mathrm{~m}$, a sediment surface roughness parameter $\left(z_{0}\right)$ of $0.001 \mathrm{~m}$, and a friction velocity $\left(u_{*}\right)$ of $0.00818 \mathrm{~m} \mathrm{~s}^{-1}$. These values of $z_{0}$ and $u_{*}$ correspond to a mean current velocity $\left(\overline{u_{x}}\right)$ of $0.1 \mathrm{~m} \mathrm{~s}^{-1}$ at $0.15 \mathrm{~m}$ above the sediment surface (Eq. 3). A discretization of $150 \times 50 \times 200$ control volumes in the $x, y$, and $z$ directions was used. The largest contribution to the flux at the measuring point was found for a point at the sediment surface located $3.3 \mathrm{~m}$ upstream from the measuring point (Fig. 2B). Further upstream from this maximum, the flux contribution tapered off over a relatively long distance. Obviously, the flux contribution along the $y$ axis exhibits symmetry around the $x$ axis (Fig. 2C).

The footprint is defined as the smallest sediment surface area that contributes $90 \%$ of the flux registered at the measuring point. A lower defining percentage reduces the size of the footprint noticeably (Fig. 3A), but the characteristic shape of the footprint is maintained. A reduction in footprint size is likewise attained when the measuring point is moved down toward the sediment surface (Fig. 3B). Again, the characteristic shape of the footprint is maintained.

For a given $\overline{u_{x}}$, the sediment surface roughness parameter $\left(z_{0}\right)$ exerts a major control on friction velocity $\left(u_{*}\right)$
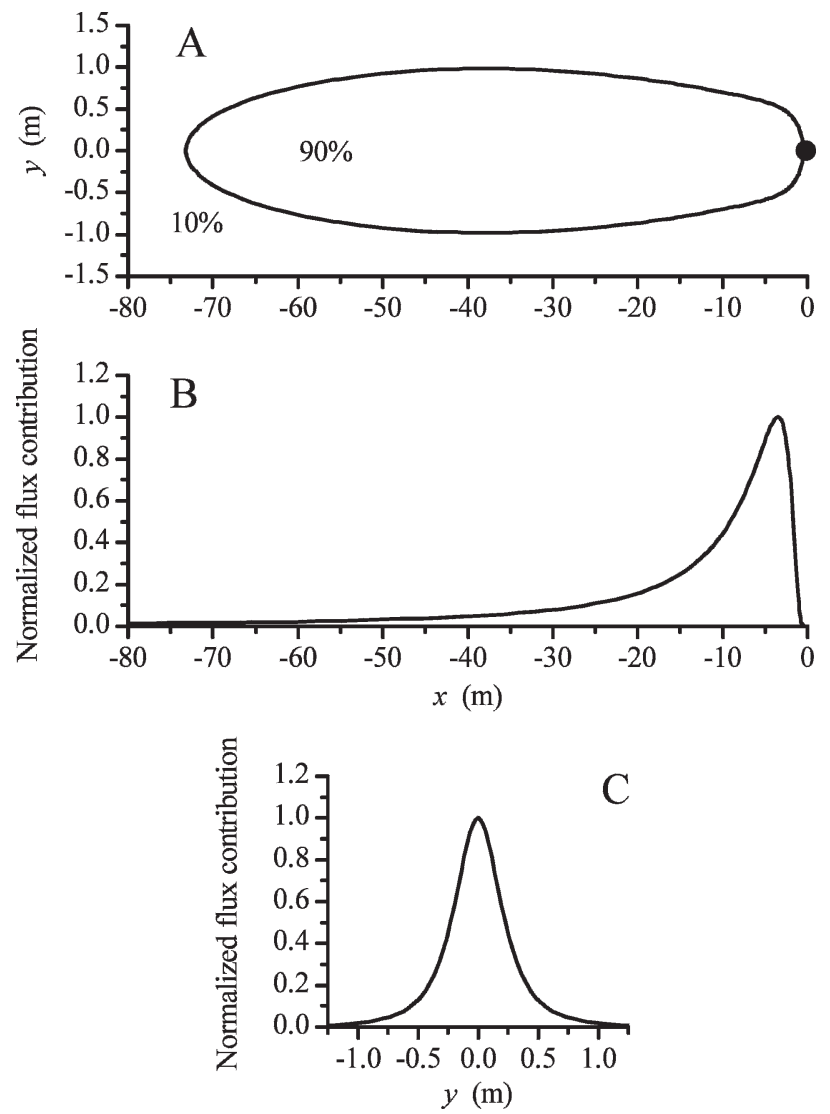

Fig. 2. (A) Typical footprint seen from above. The filled circle marks the measuring point. Ninety percent of the flux registered at the measuring point originates from the footprint, while $10 \%$ comes from the surrounding area. The footprint, some 70-m long and 2-m wide, was calculated for a water depth $(H)$ of $15 \mathrm{~m}$, a measuring height $(h)$ of $0.3 \mathrm{~m}$, a sediment surface roughness parameter $\left(z_{0}\right)$ of $0.001 \mathrm{~m}$, and a friction velocity $(u *)$ of $0.00818 \mathrm{~m} \mathrm{~s}^{-1}$. (B) The normalized flux contribution along the $x$ axis with a maximum located $3.3-\mathrm{m}$ upstream from the measuring point. (C) The normalized flux contribution along the $y$ axis.

(Eq. 3) and eddy diffusivities ( $\left.E_{x}, E_{y}, E_{z}\right)$ (Eq. 2), and thus, on the footprint (Fig. 3C). A rougher sediment surface will result in more vigorous turbulence that will transport the flux signal faster upward toward the measuring point and reduce the length of the footprint. The footprints here (Fig. 3C) indicate that footprint width is not affected by $z_{0}$. This is examined in detail below.

A strong correlation exists between footprint length and water depth (H) (Fig. 3D). The maximum values of $E_{x}, E_{y}$, and $E_{z}$ are proportional to $H$ (Eq. 2), which explains why the size of the footprint depends on $H$, at least for $H$ below a certain threshold value. For $h=0.3 \mathrm{~m}, z_{0}=0.001 \mathrm{~m}$, and $u_{*}=0.00818 \mathrm{~m} \mathrm{~s}^{-1}$, this threshold is found to be around $10 \mathrm{~m}$. For smaller $H$, the footprint becomes markedly larger, as the maximum values of $E_{x}, E_{y}$, and $E_{z}$ decrease (Eq. 2). At $H=2 \mathrm{~m}$, the footprint is some 2.5 times longer than that for $H=12 \mathrm{~m}$ (Fig. 3D). Additional footprint predictions for the same values of $h, z_{0}$, and $u_{*}$ revealed that air-water tracer exchange (Eq. 4) only affects the 

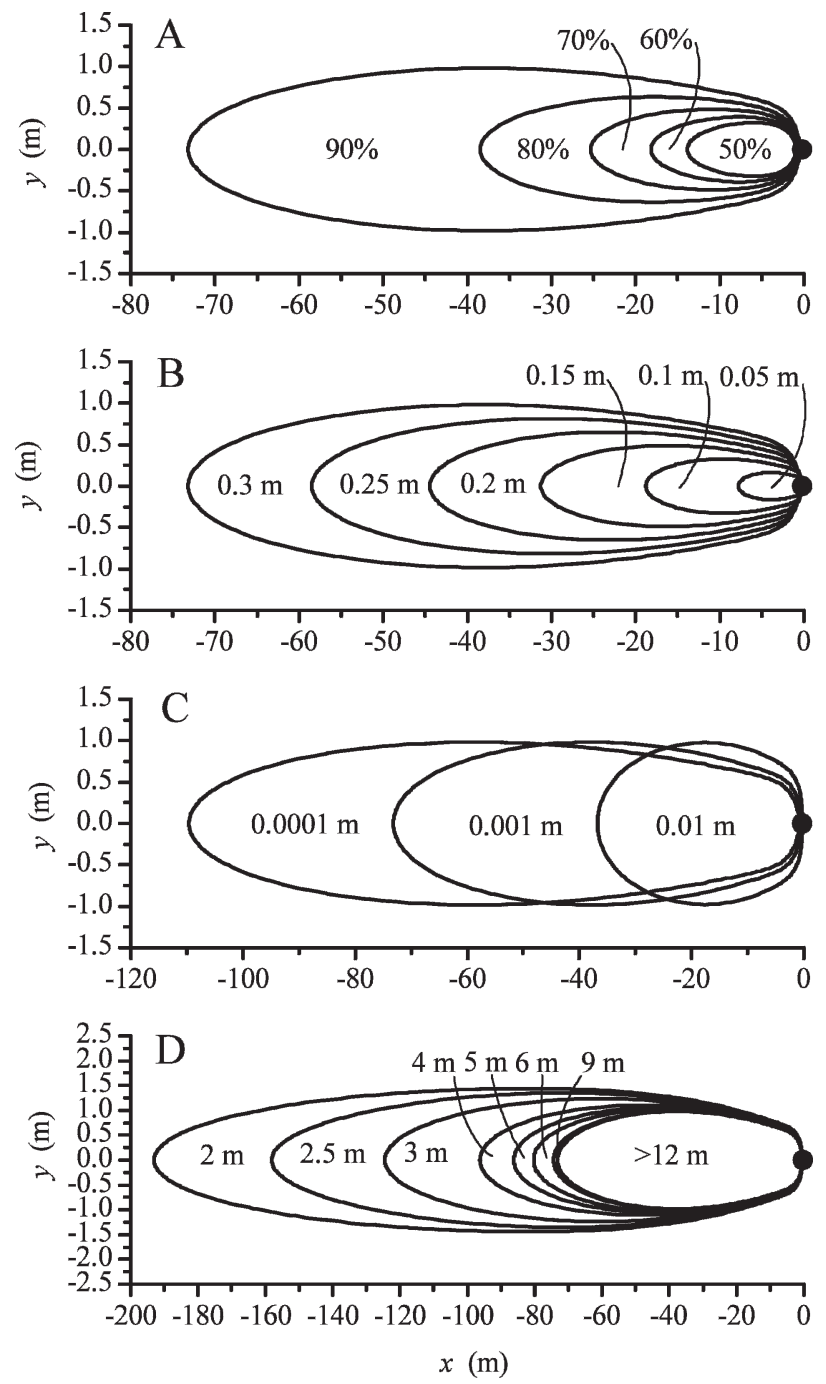

Fig. 3. (A) Footprints for different defining percentages for the footprint. All other footprints presented in this paper are defined by a percentage of $90 \%$. The footprints shown are calculated for a water depth $(H)$ of $15 \mathrm{~m}$, a measuring height $(h)$ of $0.3 \mathrm{~m}$, a sediment surface roughness parameter $\left(z_{0}\right)$ of $0.001 \mathrm{~m}$, and a friction velocity $\left(u_{*}\right)$ of $0.00818 \mathrm{~m} \mathrm{~s}^{-1}$. The filled circle marks the measuring point. (B) Footprints at different values of $h$ $\left(H=15 \mathrm{~m}, z_{0}=0.001 \mathrm{~m}, u_{*}=0.00818 \mathrm{~m} \mathrm{~s}^{-1}\right)$. (C) Footprints at different values of $z_{0}$. The $z_{0}$ values shown correspond to $u_{*}$ values of $0.00561,0.00818$, and $0.0151 \mathrm{~m} \mathrm{~s}^{-1}$ to give the same mean current velocity $0.15 \mathrm{~m}$ above the sediment surface $(H=15 \mathrm{~m}, h$ $=0.3 \mathrm{~m})$. (D) Footprints at different values of $H\left(h=0.3 \mathrm{~m}, z_{0}=\right.$ $0.001 \mathrm{~m}, u^{*}=0.00818 \mathrm{~m} \mathrm{~s}^{-1}$ ). Below a certain threshold value, here about $10 \mathrm{~m}, H$ strongly affects the footprint.

footprint for $H<2 \mathrm{~m}$. A simple comparison of realistic molecular diffusivities $(D$, Eq. 1$)$ for any soluble gases with $E_{x}, E_{y}$, and $E_{z}$ (Eq. 2) reveals that molecular diffusion is insignificant and does not affect the footprint.

For water depths large enough not to affect the footprint, comparisons can be made with results from atmospheric boundary layer research. One of the early expressions for the length of the footprint $(l)$ was derived analytically by Gash (1986) for a neutrally buoyant atmosphere, and was based on a simplified 2D formulation in the $x$ and $z$ direction (Fig. 1A). Estimating $l$ from this expression with the same parameter values as for the footprint shown in Fig. 2 gives $l=80.0 \mathrm{~m}$. A more recent expression, derived by Hsieh et al. (2000), also for a 2D neutral atmospheric boundary layer flow, gives $l=77.3 \mathrm{~m}$. Our calculation of this footprint gave $l=72.7 \mathrm{~m}$. We believe that this small difference arises primarily from the simplified 2D formulation used by Gash (1986) and Hsieh et al. (2000) rather than the full 3D formulation used in our approach.

Footprint analysis at larger water depths-We performed an extensive analysis of the footprint and its dependencies for a variety of realistic field conditions, including different mean current velocities and sediment surface roughnesses. These results were used to derive simple expressions for the length and width of the footprint and the upstream distance from the measuring point to the location with the largest flux contribution.

The first analysis was done at a constant water depth $(H)$ of $15 \mathrm{~m}$, large enough that the footprint is independent of $H$ (Fig. 3D). The mean current velocity $\left(\overline{u_{x}}\right)$ given for a height $(z)$ of $0.15 \mathrm{~m}$ above the sediment surface was varied from 0.01 to $0.5 \mathrm{~m} \mathrm{~s}^{-1}$ (Table 1). Both hydraulically smooth and rough surfaces were included in the analysis. For the former, the sediment surface roughness parameter $\left(z_{0}\right)$ was defined as (e.g., Schlichting 1979)

$$
z_{0}=\frac{v}{9 u_{*}},
$$

where $v$ is the kinematic viscosity. A value of $v=1.3$ $10^{-6} \mathrm{~m}^{2} \mathrm{~s}^{-1}\left(10^{\circ} \mathrm{C}\right)$ was used in all calculations. Values of $z_{0}$ and friction velocity $\left(u_{*}\right)$ corresponding to the specified value of $\overline{u_{x}}$ were found by combining the log profiles in Eq. 3 and Eq. 5 to obtain the following iterative expression

$$
u_{*}^{n+1}=\frac{\overline{u_{x}} \kappa}{\ln \frac{9 z u_{*}^{n}}{v}},
$$

where $n$ represents the iteration step. For the hydraulically rough sediment surfaces, $z_{0}$ was varied from 0.0001 to $0.01 \mathrm{~m}$ (Table 1 ), and values of $u_{*}$ for known values of $\overline{u_{x}}$ and $z$ were found from Eq. 3. For all 23 combinations of $\overline{u_{x}}, u_{*}$, and $z_{0}$ (Table 1), footprints were predicted for measuring heights $(h)$ of $0.05,0.1,0.15,0.2,0.25$, and $0.3 \mathrm{~m}$ above the sediment surface.

Several important characteristics can be seen from the length $(l)$ and width $(w)$ of all 138 predicted footprints and the upstream distances $\left(x_{\max }\right)$ from the measuring point to the location with the largest flux contribution (Fig. 4). Firstly, the variation of $l$ and $x_{\max }$ depends on two variables, $z_{0}$ and $h$, and is independent of $\overline{u_{x}}$ (Fig. 4A,B). The latter can be explained as follows. For any rough sediment surface with a given $z_{0}$, an increase in $\overline{u_{x}}$ leads to a faster horizontal transport of the flux signal downstream toward the measuring point. At the same time, the increase in $\overline{u_{x}}$ increases the turbulence mixing (Eq. 2), which results in faster vertical transport of the flux signal upward toward 
Table 1. Combination of parameters in the first footprint analysis performed for a water depth of $15 \mathrm{~m}$. All values of the mean current velocity $\left(\overline{u_{x}}\right)$ are specified at $0.15 \mathrm{~m}$ above the sediment surface. For each $\overline{u_{x}}$, and corresponding values of friction velocity $(u *)$ and surface roughness parameter $\left(z_{0}\right)$, the footprint was calculated for measuring heights of $0.05,0.1,0.15,0.2,0.25$, and $0.3 \mathrm{~m}$ above the sediment surface.

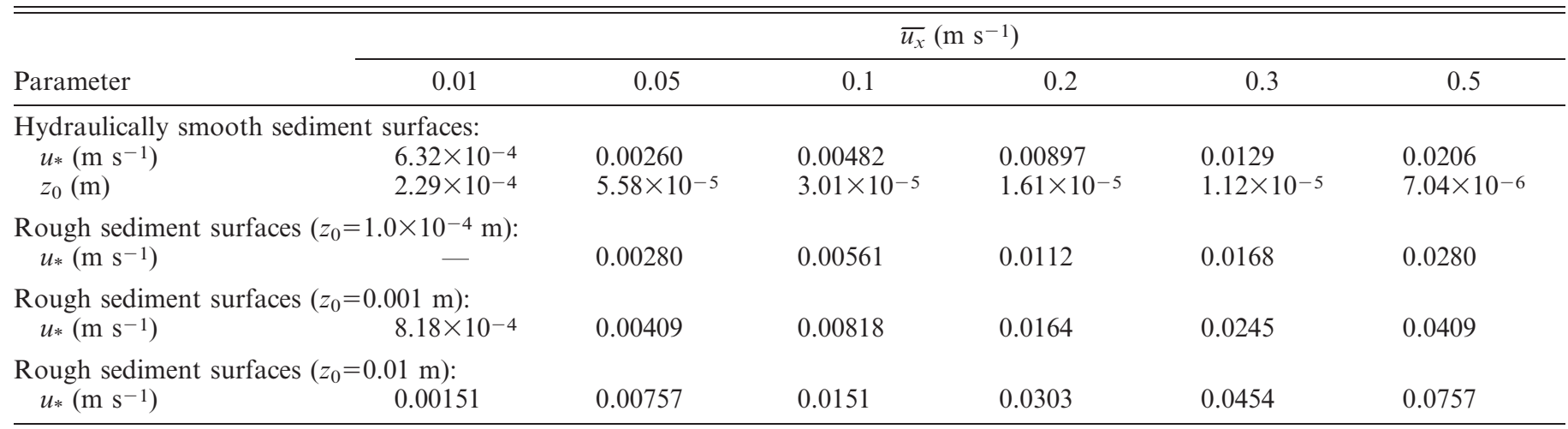

the measuring point. These two mechanisms compensate fully for one another, thereby making $l$ and $x_{\max }$ independent of $\overline{u_{x}}$. It should be noted that the expression derived by Hsieh et al. (2000) for neutrally buoyant atmosphere boundary flow shows the same independency. Secondly, the variation of $w$ depends on only one variable, $h$ (Fig. 4C), and is independent of $\overline{u_{x}}$ and $z_{0}$. This important characteristic can be explained along the same lines as the independence of $l$ and $x_{\max }$ from $\overline{u_{x}}$. This extreme simplicity allows the width of all footprints $(w)$ to be calculated from the measuring height $(h)$ via a linear fit to the data (Fig. 4C; $\left.R^{2}=1.0000\right)$ :

$$
w=6.531 h .
$$

Figure 5 shows all values of $l$ and $x_{\max }$ from Fig. 4 but plotted as a function of $z_{0}$ on a $\log$ axis. This presentation indicates a clear linear dependency for both $l$ and $x_{\max }$ in relation to $z_{0}$. Thus, linear fits of the form $a+b \log \left(z_{0}\right)$, where $a$ and $b$ are fitting parameters, result in pairs of $a$ and $b$ for both $l$ and $x_{\max }$ (Fig. 6). Further analysis reveals that $a$ for both $l$ and $x_{\max }$ can be fitted with second-degree polynomials of the form $a=a_{1}+a_{2} h+a_{3} h$, and that $b$, again for both $l$ and $x_{\max }$, can be fitted with linear fits of the form $b=b_{1} h$. Consequently, all $l$ values and $x_{\max }$ values (Fig. 4) were fitted separately with functions of the form $a_{1}$ $+a_{2} h+a_{3} h+b_{1} h \log \left(z_{0}\right)$. The resulting two fits, one for the footprint lengths $(l)$ and one for the upstream distances $\left(x_{\max }\right)$ from the measuring point to the location with the largest flux contribution, allow these two key variables to be calculated from the measuring height $(h)$ and the sediment surface roughness parameter $\left(z_{0}\right)$ as (all units in $\mathrm{m})$

$$
l=-2.783-158.7 h+159.2 h^{2}-120.8 h \log \left(z_{0}\right)
$$

and

$x_{\max }=-0.09888-11.53 h+10.25 h^{2}-6.650 h \log \left(z_{0}\right) .(9)$

These simple correlations accurately reproduce both $l\left(R^{2}\right.$
$=1.000)$ and $x_{\max }\left(R^{2}>0.9996\right)$ determined from all the detailed and involved tracer tracking simulations (Fig. 4).

Footprint analysis at smaller water depths - In the second analysis, the effect of water depth $(H)$ on the footprint was examined. This was done through multiple repetitions of the three simulations with sediment surface roughness parameters $\left(z_{0}\right)$ of $2.29 \times 10^{-4}, 0.001$, and $0.01 \mathrm{~m}$ (Table 1), and with $H$ reduced incrementally from $15 \mathrm{~m}$ to $12,9,6,5,4,3,2.5,2.0,1.75,1.5,1.25,1.0,0.75$, and $0.5 \mathrm{~m}$.

The prediction of transfer coefficients $(k)$ for air-water exchange of water soluble gases (Eq. 4) is not trivial, and site-specific $k$ values are often associated with uncertainties of several factors (Kremer et al. 2003; Borges et al. 2004). For that reason, we limited this analysis to include only water depths unaffected by this exchange. These $H$ values were identified by performing each of the simulations outlined above with two different $k$ values, one that in a practical sense was infinitely large and one that was zero. For all 90 combinations of $z_{0}, H$, and $k$, footprints were calculated for measuring heights $(h)$ of $0.05,0.1,0.15,0.2$, 0.25 , and $0.3 \mathrm{~m}$ above the sediment surface (Fig. 7), and the results were used to derive a simple correction for the footprint length $(l)$ given by Eq. 8 .

The results (Fig. 7) revealed that three regimes of $H$ exist in which the dependency of $l$ varies: one where $l$ is independent of $H$ and $k$, one where $l$ depends on $H$ but is independent of $k$, and one where $l$ depends on both $H$ and $k$. One characteristic of the simulations with a zero $k$ value (Fig. 7, filled circles) is that $l$ increases rapidly below certain $H$ values and diverges markedly from the simulations with an infinitively large $k$ value (open circles). Water depths $(H)$ where the air-water transfer rate affects the length of the footprint are proportional to the measuring height $(h)$ and can be estimated as

$$
H=6.7 h \text {. }
$$

Only $H$ values larger than this threshold are considered here, and the selected data were represented by one single 

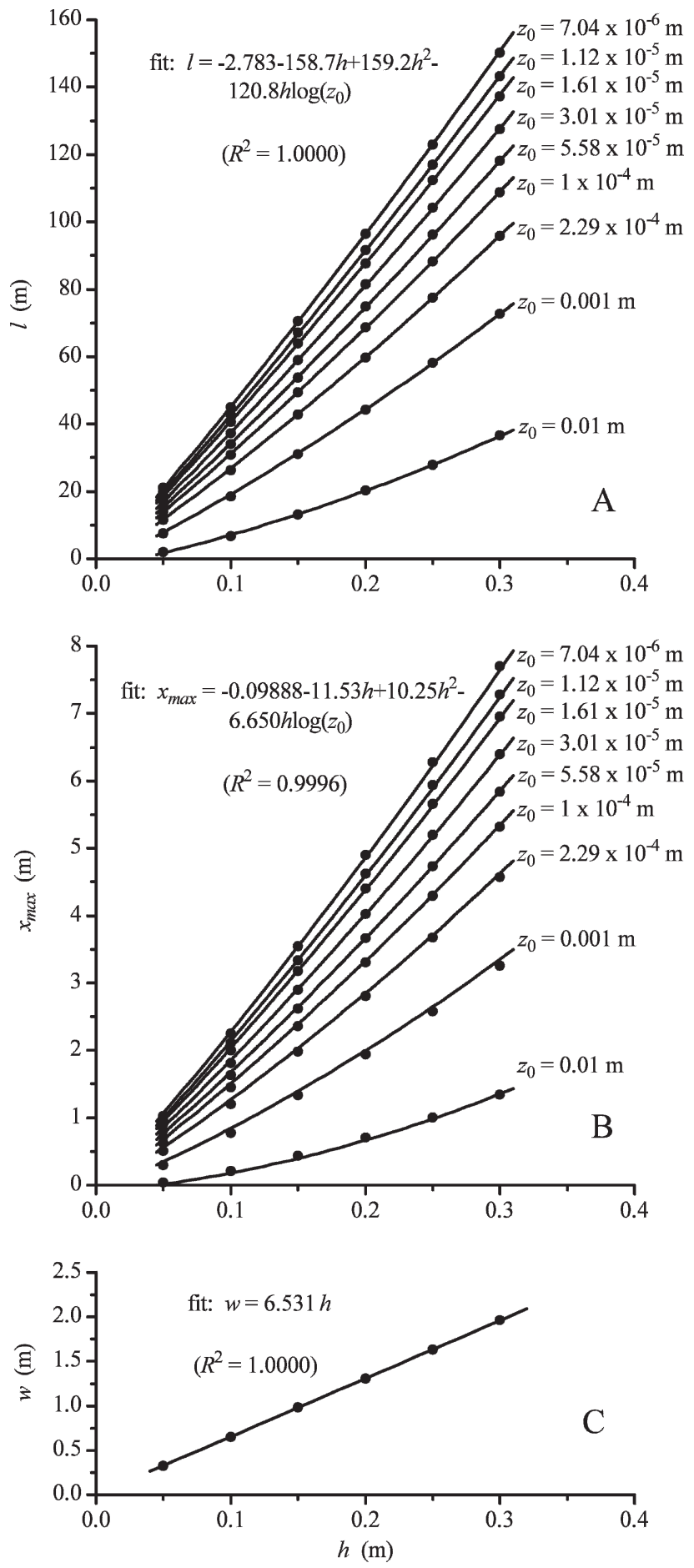

Fig. 4. (A) Length of footprints ( $l$, filled circles) as a function of measuring height $(h)$ for all simulations outlined in Table 1. These simulations assume a water depth $(H)$ of $15 \mathrm{~m}$. An important result is that $l$ depends on $h$ and the sediment surface roughness parameter $\left(z_{0}\right)$, but is independent of the mean current velocity $\left(\overline{u_{x}}\right)$. The fit (lines) is derived in the text. (B) Same as panel A but for the upstream distance $\left(x_{\max }\right)$ from the measuring point to the location with the largest flux contribution. (C) Width of footprints ( $w$, filled circles) as a function of $h$ for all simulations outlined in Table 1. An important result is that $w$ depends on $h$ but is independent of $z_{0}$ and $\overline{u_{x}}$. The simple fit (line) reproduces the simulated data well.
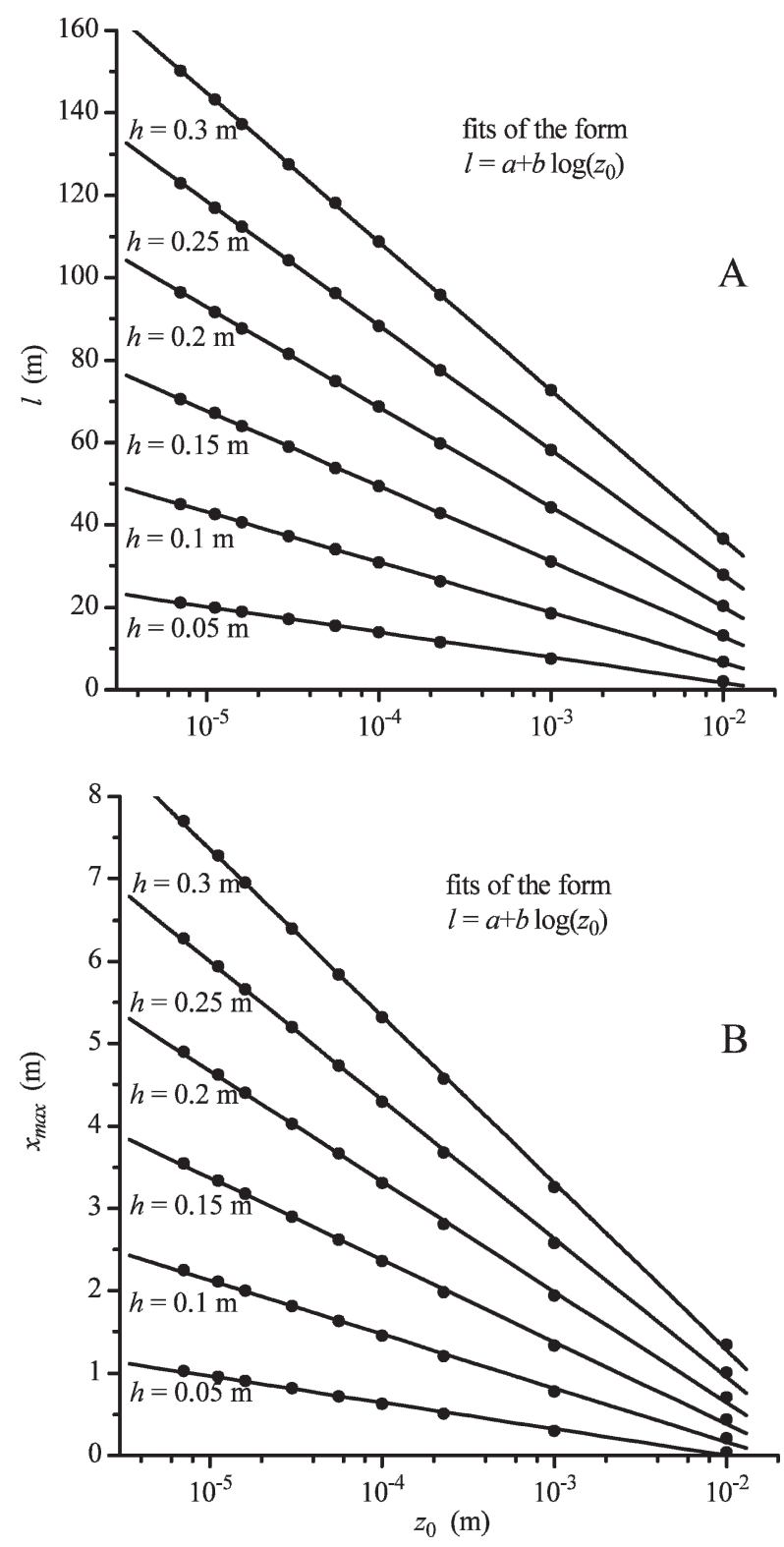

Fig. 5. (A) Length of footprints ( $l$, filled circles) plotted as a $\log$ function of the sediment surface roughness parameter $\left(z_{0}\right)$ for all simulations outlined in Table 1 . This presentation of the data allows $l$ to be described by linear fits (lines) for each measuring height $(h)$. (B) Same as panel A but for the upstream distance $\left(x_{\max }\right)$ from the measuring point to the location with the largest flux contribution.

fitting function through a two-step scaling process. First, for each given value of $z_{0}$ and $h$ (Fig. 7), all corresponding $l$ values were divided by the $l$ value for $H=15 \mathrm{~m}$. For each $h$ value, this gave one series of scaled $l$ values (data not shown) that can be described by a function of the form $1+$ $c_{1} \exp \left(-c_{2} H\right)$, where $c_{1}$ and $c_{2}$ are fitting parameters. A further analysis of these scaled $l$ values revealed that all data could be represented by one single function after normalizing all $H$ values with $c_{3} h$, where $c_{3}$ is a scaling parameter. The resulting function is of the form $1+c_{1}$ $\exp \left(-c_{2} H /\left[c_{3} h\right]\right)$, which simplifies to $1+c_{1} \exp \left(-c_{4} H / h\right)$, with 

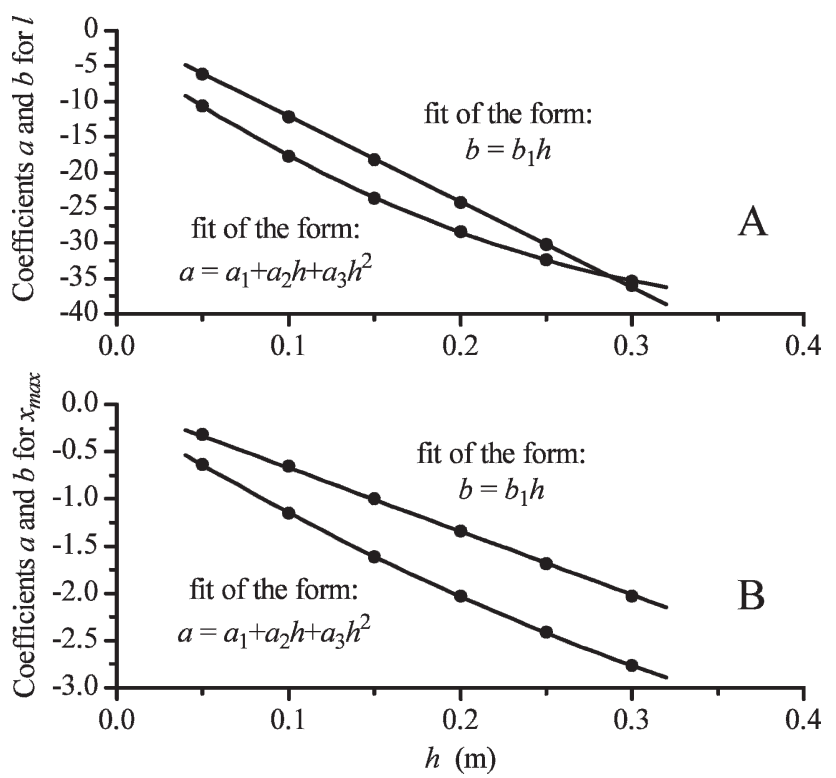

Fig. 6. (A) Coefficients $a$ and $b$ (filled circles) from the linear fits of footprint lengths $(l)$ in Fig. 5A as a function of measuring height $(h)$. This presentation of the coefficients allows $a$ and $b$ to be fitted (lines) by a second-degree polynomial and a line. (B) Same as panel A but for the upstream distance $\left(x_{\max }\right)$ from the measuring point to the location with the largest flux contribution.

the unique fitting parameters $c_{1}$ and $c_{4}$. Values for $c_{1}$ and $c_{4}$ were found by fitting all scaled $l$ values as a function of $H / h$ $\left(R^{2}=0.9746\right.$; Fig. 8). Thus, for smaller water depths $(H)$ and a given measuring height $(h)$, the length of the footprint ( $l$ ) can be estimated as $l$ calculated from Eq. 8 multiplied by the following factor

$$
F=1+8.347 \exp \left(-0.2453 \frac{H}{h}\right) .
$$

Water depths $(H)$ where this correction is required depend on the measuring height $(h)$ and can be calculated as

$$
H \leq 27 h,
$$

which is equivalent to a correction of $1 \%$ according to Eq. 11. The high accuracy of Eqs. 8 and 11, despite their simplicity, is demonstrated in Fig. 9, which shows $l$ from the detailed tracer tracking simulations and the predictions made by these two expressions. A similar analysis of the upstream distance $\left(x_{\max }\right)$ to the location that contributes the strongest flux signal revealed that $x_{\max }$ is virtually independent of $H$.

Estimation of sediment surface roughness parameter-Of the three parameters in Eqs. 8, 9, and 11, the water depth $(H)$ and the measuring height $(h)$ are usually easy to determine. The latter is in fact among the standard output parameters from the latest versions of some acoustic Doppler velocimeters. On the contrary, the sediment surface roughness parameter $\left(z_{0}\right)$ is more challenging to
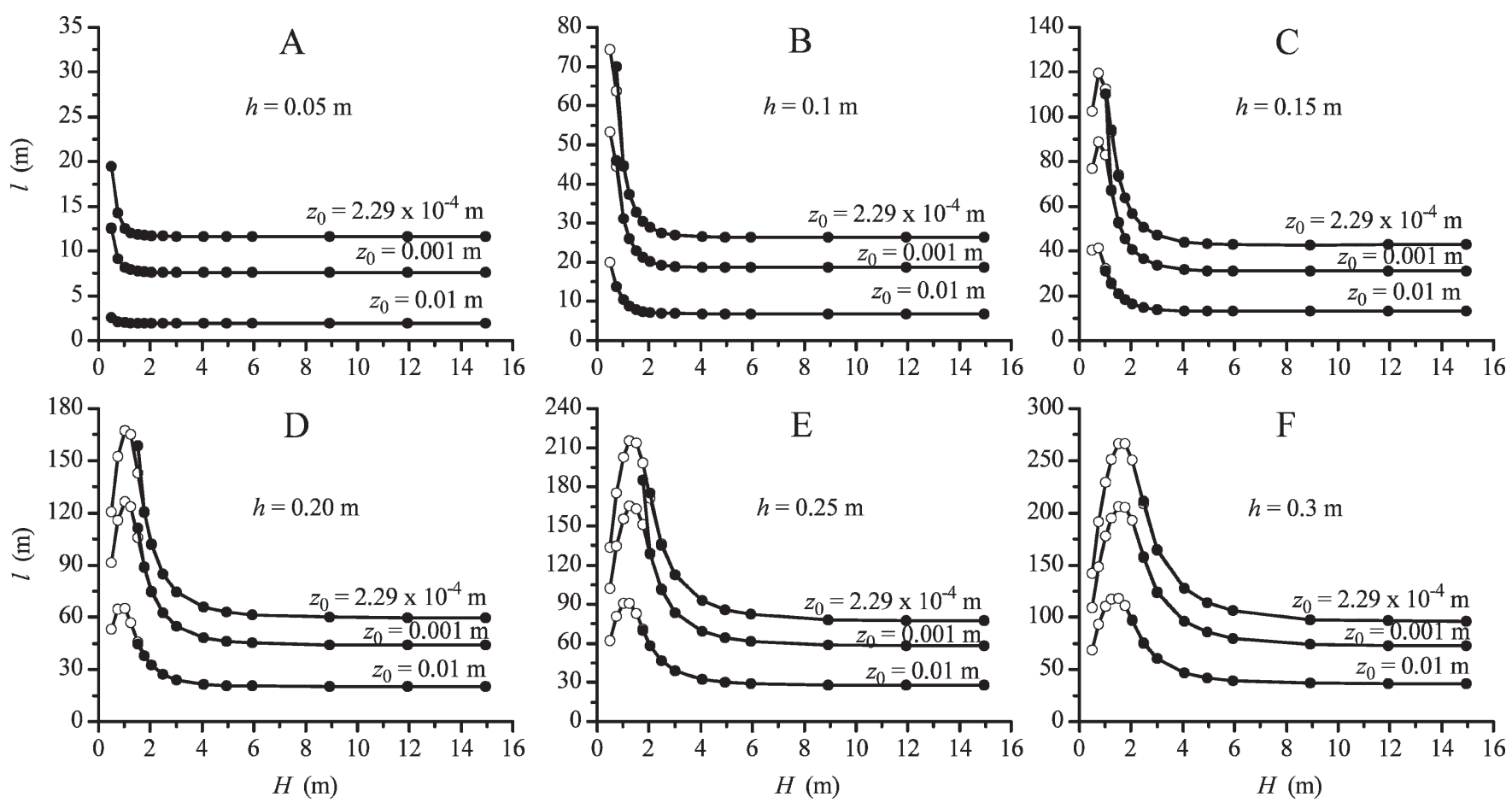

Fig. 7. (A-F) Length of footprints $(l)$ as a function of water depth $(H)$ for six measuring heights $(h)$, three sediment surface roughness parameters $\left(z_{0}\right)$, and two air-water exchange coefficients $(k)$, one infinitively large (lines with open circles) and one equal to zero (lines with filled circles). For the latter and below certain $H$ values, $l$ increases dramatically and falls outside the scale used here. Only $l$ values independent of $k$ are used in the further analysis. 


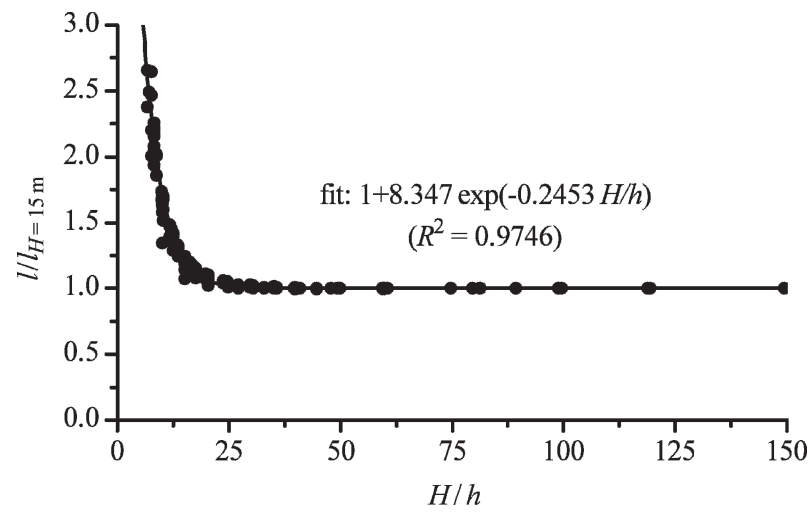

Fig. 8. Data from Fig. 7 (filled circles), after normalizing the lengths of footprints $(l)$ with $l$ values for a water depth $(H)$ of $15 \mathrm{~m}$ and $H$ values with the measuring height $(h)$. This presentation allows all data from Fig. 7 that are independent of the air-water exchange coefficients $(k)$ to be described by one single exponential fitting function (line).

assess. However, eddy correlation measurements usually include high temporal-resolution recordings of all three velocity components $\left(u_{x}, u_{y}, u_{z}\right)$, from which $z_{0}$ can be extracted as follows. The friction velocity $\left(u_{*}\right)$ in the turbulent flow field over the sediment surface is defined as (e.g., Stull 1988; Garratt 1994; Dade et al. 2001)

$$
u_{*}=\left({\overline{u_{x}^{\prime} u_{z}^{\prime}}}^{2}+{\overline{u_{y}^{\prime} u_{z}^{\prime}}}^{2}\right)^{1 / 4},
$$

where $u_{x}^{\prime}, u_{y}^{\prime}$, and $u_{z}^{\prime}$ are the fluctuating velocity components in the $x, y$, and $z$ direction (Fig. 1), within the assumed constant stress layer (Eq. 3), and the bar symbolizes an averaging over time. It should be noted that the contribution to $u_{*}$ through the term $\overline{u_{y}^{\prime} u_{z}^{\prime}}$ is often small and can be neglected in channel flows.

The separation of measured quantities (e.g., $u_{x}$ ) into time series of fluctuating components (e.g., $u_{x}^{\prime}$ ) and time series of mean components (e.g., $\overline{u_{x}}$ ) is a common practice in analysis of turbulent motions (e.g., Stanišić 1985; Boudreau 1997; Dade et al. 2001). Further, the estimation of $\overline{u_{x}^{\prime} u_{z}^{\prime}}$ and $\overline{u_{y}^{\prime} u_{z}^{\prime}}$ is essentially equivalent to calculating the eddy correlation scalar flux, $\overline{C^{\prime} u_{z}^{\prime}}$ (Berg et al. 2003), and it can be done in a two-step process as follows. First, assuming time-invariant conditions, i.e., where no change in size or direction of the current occurs, a coordinate rotation is performed on the raw velocity measurements. This rotation eliminates errors due to so-called sensor tilt and aligns the mean current direction with the $x$ axis, while the mean velocities in both the $y$ and $z$ direction $\left(\overline{u_{y}}, \overline{u_{z}}\right)$ are nullified (e.g., Aubinet et al. 2000; Lee et al. 2004). This orientation is in accordance with the coordinate system adopted here (Fig. 1). Since $\overline{u_{y}}=\overline{u_{z}}=0$ after this rotation, $u_{y}^{\prime}=\overline{u_{y}}$ and $u_{z}^{\prime}$ $=\bar{u}_{z}$, and the remaining variable in Eq. $13, u_{x}^{\prime}$, is calculated as $u_{x}^{\prime}=u_{x}-\overline{u_{x}}$, where $\overline{u_{x}}$ for example can be defined as the simple average of the entire time series of $u_{x}$. This particular definition of $u_{x}^{\prime}$ removes the simple means from the measured data. Other procedures exist to isolate $u_{x}^{\prime}$, for example, through linear detrending of the measured data, or more advanced, through filtering the recorded data (e.g., Aubinet et al. 2000; Moncrieff et al. 2004).

With $u_{*}$ known, the sediment surface roughness parameter $\left(z_{0}\right)$ can be calculated as the only unknown in the
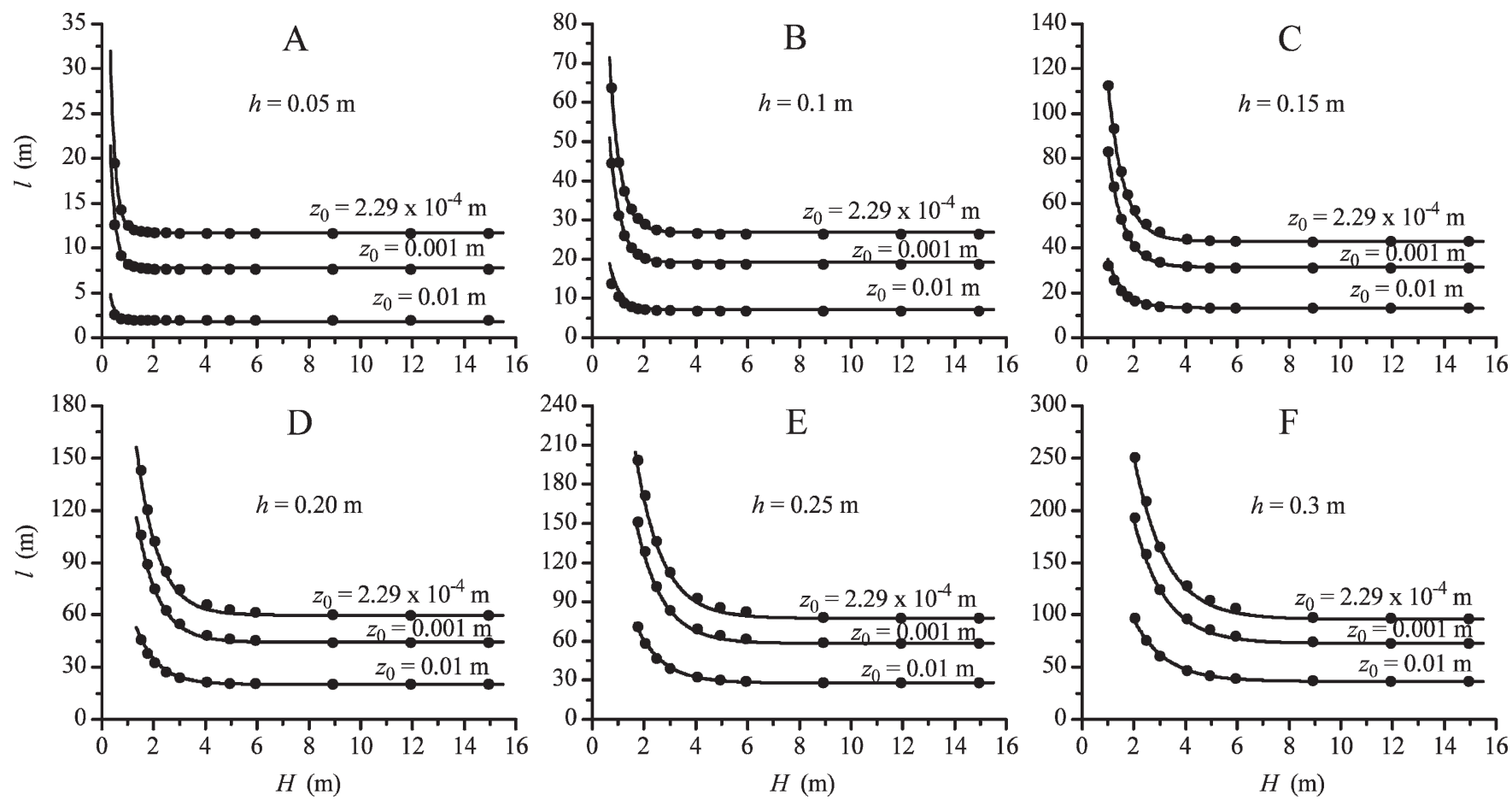

Fig. 9. (A-F) Test of the simple expressions (Eqs. 8 and 11, lines) for the length of the footprint $(l)$ against all simulations (filled circles) from Fig. 7 that are independent of the air-water exchange coefficients $(k)$. 
classic log profile (Eq. 3) from the measuring height (h), the mean current velocity $\left(\overline{u_{x}}\right)$, and von Karman's constant $(\kappa$ $=0.41)$ as

$$
z_{0}=\frac{h}{\exp \left(\frac{\overline{u_{x}} \kappa}{u_{*}}\right)}
$$

As an example, we applied the described equations to one of the sites we visited during our first eddy correlation measurements (Berg et al. 2003). These measurements were made in the Wümme River near Bremen, Germany, where three 10-min time series of $u_{x}, u_{y}$, and $u_{z}$ were sampled at a frequency of $25 \mathrm{~Hz}$ for $h=0.15 \mathrm{~m}$ and at $H=1 \mathrm{~m}$. After coordinate rotation, which was practically the same for all three time series, the mean current velocity $\left(\overline{u_{x}}\right)$ averaged $0.143 \pm 0.002 \mathrm{~m} \mathrm{~s}^{-1}$. The calculated values of $u_{*}$ and $z_{0}$ are shown in Fig. 10, as is the length of the footprint $(l)$ estimated from Eqs. 8 and 11. For comparison, estimates of $u_{*}, z_{0}$, and $l$ based on linear detrending and filtering through running averaging of the same data are also shown. In all three cases, the relative standard error of $l$ is $<10 \%$. It should be noted that the term $\overline{u_{y}^{\prime} u_{z}^{\prime}}$ in Eq. 13 only contributed $0.5 \%$ to $u_{*}$, revealing that this river site, at least in some sense, can be classified as an ideal channel flow.

Evaluation of derived expressions-The potential uncertainties associated with using the derived expressions rather than performing detailed tracer tracking simulations are insignificant (Figs. 4, 9). In comparison, larger uncertainties are likely to arise from the assumptions that the tracer tracking simulations are based upon. Of these, the expressions for the eddy diffusivities (Eq. 2) and the isotropic nature of the turbulence in the near-bottom flow are expected to be the most critical, and we examined the effects of these assumptions in detail.

A number of alternative expressions to Eq. 2 exist for the vertical eddy diffusivity $\left(E_{z}\right)$. For example, atmospheric and marine boundary layer studies have used an eddy diffusivity of the form $E_{z}=\kappa u_{*} z \exp \left(-z / l_{c}\right)$, where $l_{c}$ is a characteristic length scale (Businger and Arya 1974; Long 1981; Wiberg and Smith 1983). In this evaluation, we use $l_{c}$ $=H / 2$. Other studies have found that $E_{z}=\kappa u_{*} z \exp (-[z / H]$ $\left.-3.3[z / H]^{2}+2.2[z / H]^{3}\right)$ yields accurate velocity profiles for channel flows (Long 1981; Gelfenbaum and Smith 1986; Wiberg and Rubin 1989). The deviations of these two expressions from Eq. 2 are rather large at some depths, with a maximum of $27 \%$ (Fig. 11), whereas the depthintegrated means of all three expressions are similar within $3 \%$. The effect of these differences on the footprint was determined in a sensitivity analysis where the three expressions were used in additional tracer tracking simulations. Presumably due to the comparable means, the same footprint was predicted within a few percent (data not shown).

The assumption of isotropic turbulence in the nearbottom flow is rather crude since cross comparisons of longitudinal, transverse, and vertical eddy diffusivities $\left(E_{x}\right.$, $E_{y}, E_{z}$ ) typically reveal differences in size of several factors
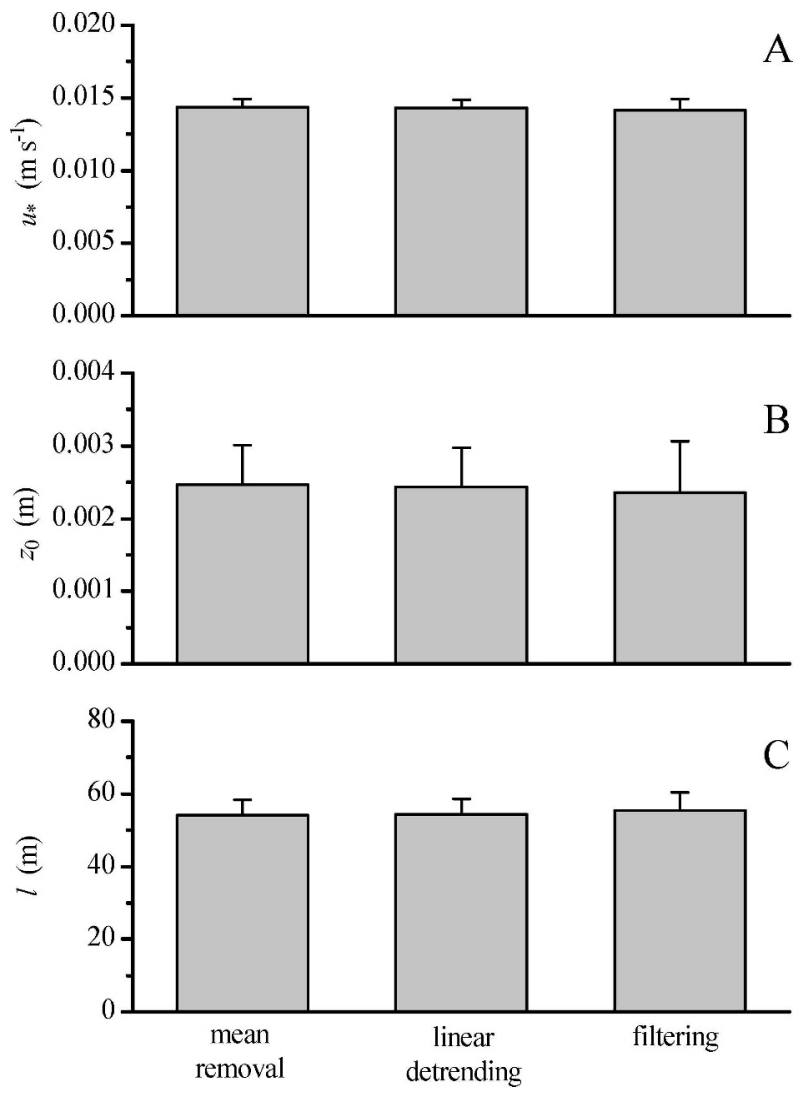

Fig. 10. (A-C) Friction velocity $\left(u_{*}\right)$, sediment surface roughness parameter $\left(z_{0}\right)$, and length of the footprint $(l)$ estimated for a sandy river sediment in Wümme River, Germany (see Berg et al. 2003 for details). The estimates were based on three 10-min time series of velocities $\left(u_{x}, u_{y}, u_{z}\right)$ sampled at $25 \mathrm{~Hz}$ at a measuring height $(h)$ of $0.15 \mathrm{~m}$ and using three common procedures for extracting eddy correlation fluxes. Error bars represent $+1 \mathrm{SE}$ $(n=3)$.

(e.g., Fischer 1979). However, a first-order estimate of sitespecific anisotropy can be attained directly from eddy correlation measurements that include high-temporal-resolution records of all three velocity components, $u_{x}, u_{y}$, and $u_{z}$. The key assumption is that the $E_{x}$, for example, can be approximated as $I_{x} \sigma_{x}^{2}$ where $I_{x}$ is the integral time scale of the fluctuating velocity in the $x$ direction, $u_{x}^{\prime}$, and $\sigma_{x}$ is the standard deviation of $u_{x}^{\prime}$ (e.g., Raupach 1988; Hsieh et al. 1997). A similar assumption is made for the $y$ and $z$ directions. The level of anisotropy for the $x$ and $y$ directions relative to the $z$ direction can then be expressed as

$$
\text { and } \begin{aligned}
\frac{E_{x}}{E_{z}} & =\frac{I_{x} \sigma_{x}^{2}}{I_{z} \sigma_{z}^{2}} \\
\frac{E_{y}}{E_{z}} & =\frac{I_{y} \sigma_{y}^{2}}{I_{z} \sigma_{z}^{2}} .
\end{aligned}
$$

The value of $I_{x}$ in Eq. 15 can be estimated as the integral of the autocorrelation function of $u_{x}^{\prime}$. According to Stull (1988), the discrete definition of this function, $R_{x j}$, for a time 


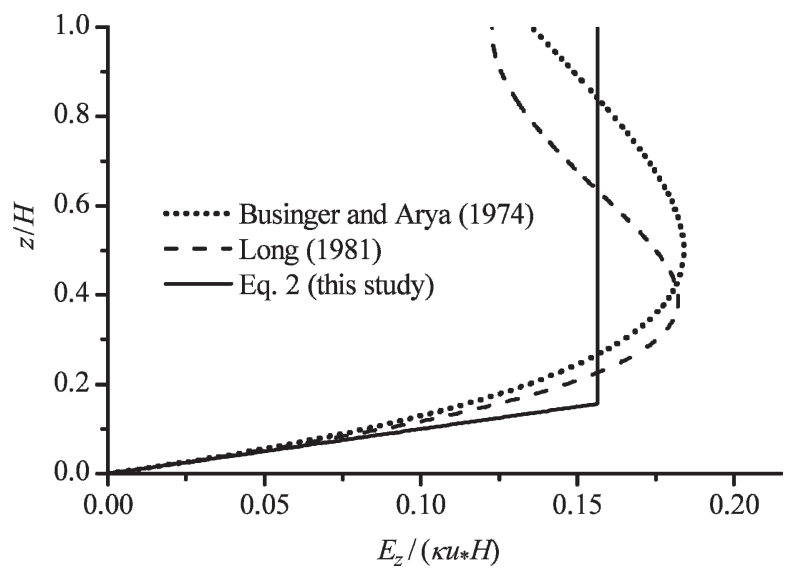

Fig. 11. Dimensionless eddy diffusivities $\left(E_{z} /\left[\kappa u_{*} H\right]\right)$ as a function of dimensionless height $(z / H)$ above the sediment surface. Tracer tracking simulations reveal that the different expressions for $E_{z}$ give the same footprint predictions within a few percent.

series of $N$ values of $u_{x}^{\prime}$ yields

$$
\begin{aligned}
& R_{x j}=\frac{\sum_{k=1}^{N-j}\left(u_{x_{k}}^{\prime}-\overline{u_{x_{k}}^{\prime}}\right)\left(u_{x_{k+j}}^{\prime}-\overline{u_{x_{k+j}}^{\prime}}\right)}{\left(\sum_{k=1}^{N-j}\left(u_{x_{k}}^{\prime}-\overline{u_{x_{k}}^{\prime}}\right)^{2}\right)^{\frac{1}{2}}\left(\sum_{k=1}^{N-j}\left(u_{x_{k+j}}^{\prime}-\overline{u_{x_{k+j}}^{\prime}}\right)^{2}\right)^{\frac{1}{2}}} \\
& \overline{u_{x_{k}}^{\prime}}=\frac{1}{N-j} \sum_{k=1}^{N-j} u_{x_{k}}^{\prime} \\
& \overline{u_{x_{k+j}}^{\prime}}=\frac{1}{N-j} \sum_{k=1}^{N-j} u_{x_{k+j}^{\prime}}^{\prime}
\end{aligned}
$$

where $j$ and $k$ are indices. Thus, $R_{x j}$ is computed for $j=0$ to $j=N / 2$, and the result is integrated from $j=0$ to the $j$ value where $R_{x j}=0$ to give $I_{x}$. Integral time scales of the fluctuating velocities in the $y$ and $z$ directions are calculated the same way.

As an example, we applied these equations to the Wümme River site for which we had previously estimated the sediment surface roughness parameter. The three 10min time series for each fluctuation velocity component, $u_{x}^{\prime}$, $u_{y}^{\prime}$, and $u_{z}^{\prime}$ were obtained by coordinate rotation followed by removal of the simple mean as described above. The levels of anisotropy, according to Eq. 15, were high and practically the same for all three time series (Fig. 12).

As a second step, we investigated how different levels of anisotropy influence the size and shape of the footprint. This was done first for the $x$ direction and then for the $y$ direction (Fig. 1). One can argue that the largest effect of anisotropy on the footprint in the $x$ direction should be expected at a large sediment surface roughness $\left(z_{0}\right)$ in

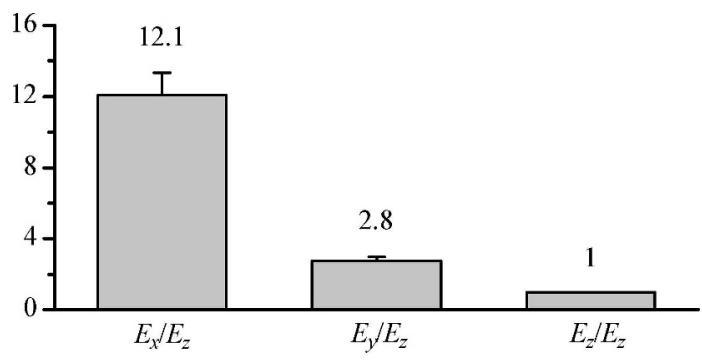

Fig. 12. Estimated levels of levels of anisotropic turbulence for Wümme River, Germany (see Berg et al. 2003 for details) shown as the longitudinal $\left(E_{x}\right)$ and transverse $\left(E_{y}\right)$ eddy diffusivity normalized by the vertical eddy diffusivity $\left(E_{z}\right)$. Error bars are 1 SE $(n=3)$.

combination with small current velocity $\left(\overline{u_{x}}\right)$. For that reason, we chose an end-member combination of these parameters used in our previous analysis of $z_{0}=0.01 \mathrm{~m}$ and $\overline{u_{x}}=0.01 \mathrm{~m} \mathrm{~s}^{-1}$, equivalent to a friction velocity of $0.00151 \mathrm{~m} \mathrm{~s}^{-1}$ (Table 1). In a sensitivity analysis, we
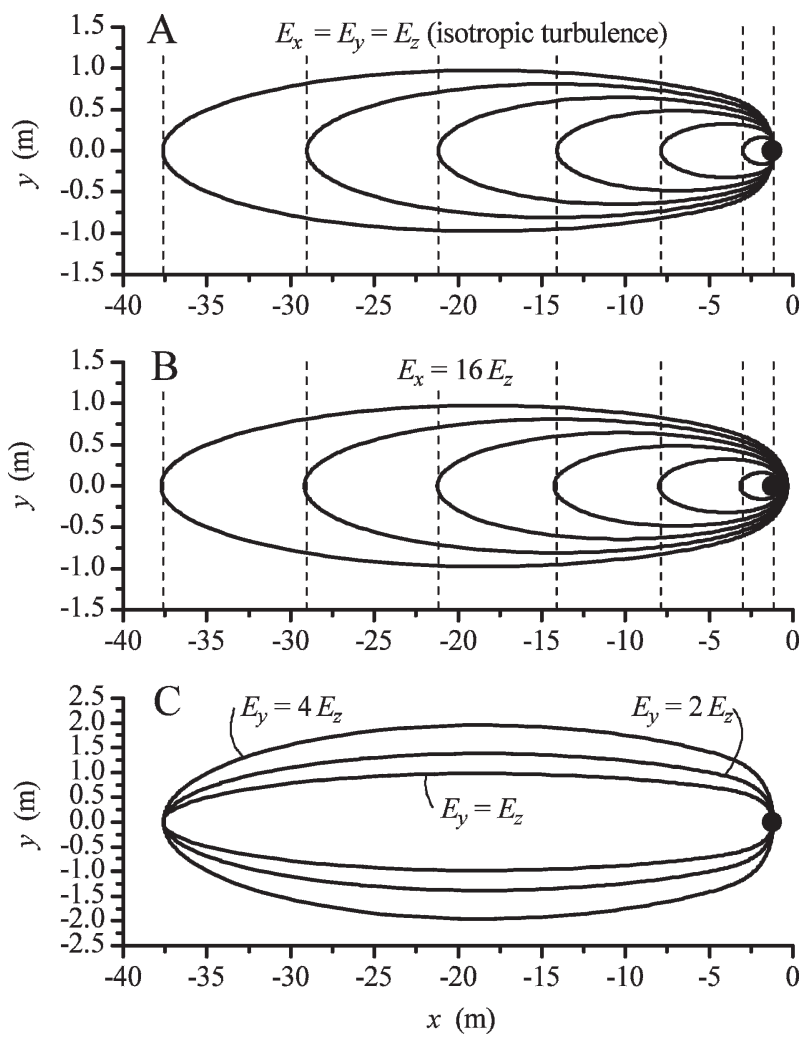

Fig. 13. (A) Footprints for isotropic turbulence for measuring heights $(h)$ of $0.3,0.25,0.2,0.15,0.1$, and $0.05 \mathrm{~m}$, a sediment surface roughness parameter $\left(z_{0}\right)$ of $0.01 \mathrm{~m}$, a friction velocity $\left(u_{*}\right)$ of $0.00151 \mathrm{~m} \mathrm{~s}^{-1}$, and a water depth $(H)$ of $15 \mathrm{~m}$. The dashed vertical lines mark the longitudinal boundaries of the footprints. (B) Same as panel A but for anisotropic turbulence with a ratio of 16 between the longitudinal $\left(E_{x}\right)$ and the vertical $\left(E_{z}\right)$ eddy diffusivity. (C) Footprints for different ratios of the transverse $\left(E_{y}\right)$ and the vertical $\left(E_{z}\right)$ eddy diffusivity $\left(h=0.3 \mathrm{~m}, z_{0}=0.01 \mathrm{~m}\right.$, $\left.u_{*}=0.00151 \mathrm{~m} \mathrm{~s}^{-1}\right)$. 
imposed different levels of anisotropy in the $x$ direction of up to $E_{x} / E_{z}=16$ and found only little effect on the footprint relative to that of isotropic turbulence (Fig. 13A vs. 13B). The difference in location of the upstream border of the footprint was barely visible, and the downstream border changed only slightly. These results suggest that anisotropy in the $x$ direction is not important for the size and shape of the footprint.

In another sensitivity analysis, where we imposed different levels of anisotropy in the $y$ direction, we found a clear effect on the footprint (Fig. 13C). Whereas the length of the footprint was unaffected due to the dominant role of advective transport in the $x$ direction, the width increased notably as the result of the increased mixing in the $y$ direction. The relative increase in width can be estimated as $\sqrt{E_{y} / E_{z}}$. Additional simulations for other combinations of sediment surface roughness and friction velocity revealed the same relative increase in footprint width.

In summary, we believe that the derived simple expressions for the length $(l)$ and width $(w)$ of the footprint and the upstream distance $\left(x_{\max }\right)$ from the measuring point to the location with the largest flux contribution are valuable tools for planning and interpretation of subaqueous eddy correlation measurements. Our analysis further suggests that $l$ and $x_{\max }$ are not, in a practical sense, affected at even high levels of anisotropic turbulence. In contrast, $w$ is affected, and we have identified a simple correction for this parameter. Finally, we described methodologies for estimating the sediment surface roughness parameter and the level of anisotropy in the turbulent bottom water directly from eddy correlation measurements. The field conditions we considered in this study include a broad variety of water depths and sediment surface roughnesses exposed to different unidirectional mean current velocities. We further limited our work to field conditions with negligible influence from surface waves and insignificant watercolumn density stratification.

\section{References}

Aubinet, M., A. Grelle, A. Ibrom, Ü. Rannik, J. Moncrieff, T. Foken, A. S. Kowalski, P. H. Martin, P. Berbigier, C. Bernhofer, R. Clement, J. Elbers, A. Granier, T. Grünwald, K. Morgenstern, K. Pilegaard, C. Rebmann, W. Snijders, R. Valentini, and T. Vesala. 2000. Estimates of the annual net carbon and water exchange of forests: The EUROFLUX methodology. Adv. Ecol. Res. 30: 113-175.

Baldocchi, D. D., B. B. Hicks, and T. P. Meyers. 1988. Measuring biosphere-atmosphere exchanges of biologically related gases with micrometeorological methods. Ecology 69: $1131-1340$

Berg, P., H. Røy, F. Janssen, V. Meyer, B. B. Jørgensen, M. Huettel, And D. DE Beer. 2003. Oxygen uptake by aquatic sediments measured with a novel non-invasive eddy correlation technique. Mar. Ecol. Prog. Ser. 261: 75-83.

Borges, A. V., B. Delille, L. S. Schiettecatte, F. Gazeau, G. Abril, And M. Frankignoulle. 2004. Gas transfer velocities of $\mathrm{CO}_{2}$ in three European estuaries (Randers Fjord, Scheldt, and Thames). Limnol. Oceanogr. 49: 1630-1641.

Boudreau, B. P. 1997. Diagenetic models and their implementation. Springer-Verlag.
2001. Solute transport above the sediment-water interface, p. 104-126. In B. P. Boudreau and B. B. Jørgensen [eds.], The Benthic boundary layer. Oxford Univ. Press.

Businger, J. A., And S. P. S. Arya. 1974. Height of the mixed layer in the stably stratified planetary boundary layer, p. 73-92. In F. N. Frenkiel, R. E. Munn, H. E. Landsberg and J. van Mieghem [eds.], Advances in Geophysics. Academic Press.

Carnahan, B., H. A. Luther, and J. O. Wilkes. 1969. Applied numerical methods. Wiley.

Dade, W. B., A. J. Hogg, and B. P. Boudreau. 2001. Physics of flow above the sediment-water interface, p. 3-43. In B. P. Boudreau and B. B. Jørgensen [eds.], The benthic boundary layer. Oxford Univ. Press.

Douglas, J. 1955. On the numerical integration of $\partial^{2} u / \partial x^{2}+\partial^{2} u /$ $\partial y^{2}=\partial u / \partial t$ by implicit methods. J. Soc. Indust. Appl. Math. 3: 42-65.

Fischer, H. B. 1979. Mixing in inland and coastal waters. Academic Press.

Garratt, J. R. 1994. The atmospheric boundary layer. Cambridge Univ. Press.

Gash, J. H. C. 1986. A note on estimating the effects of limited fetch on micrometeorological evaporation measurements. Bound.-Lay. Meteorol. 35: 409-413.

Gelfenbaum, G., AND J. D. Smith. 1986. Experimental evaluation of a generalized suspended-sediment transport theory, p. 133-144. In R. J. Knight and J. R. McLean [eds.], Shelf sands and sandstones, Memoir II. Canadian Society of Petroleum Geologists.

Hsieh, C. I., G. Katul, and T. W. Chi. 2000. An approximate analytical model for footprint estimation of scalar fluxes in thermally stratified atmospheric flows. Adv. Water Resour. 23: 765-772.

, G. Katul, J. Schiedge, J. T. Sigmon, And K. K. Knoerr. 1997. The Lagrangian stochastic model for fetch and latent heat flux estimation above uniform and nonuniform terrain. Water Resour. Res. 33: 427-438.

Kremer, J. N., A. Reischauer, And C. D’Avanzo. 2003. Estuaryspecific variation in the air-water gas exchange coefficient for oxygen. Estuaries 26: 829-836.

Kuwae, T., K. Kamio, T. Inoue, E. Miyoshi, and Y. Uchiyama. 2006. Oxygen exchange flux between sediment and water in an intertidal sandflat, measured in situ by the eddy-correlation method. Mar. Ecol. Prog. Ser. 307: 59-68.

Leclerc, M. Y., AND G. W. Thurtell. 1990. Footprint prediction of scalar fluxes using Markovian analysis. Bound.-Lay. Meteorol. 52: 247-258.

Lee, X., J. Finnigan, and K. T. Paw U. 2004. Coordinate systems and flux bias error, p. 33-99. In X. Lee, W. Massman and B. Law [eds.], Handbook of micrometeorology. A guide for surface flux measurement and analysis. Kluwer.

Liss, P. S., AND P. G. Slater. 1974. Flux of gasses across the airsea interface. Nature 247: 181-184.

LonG, C. E. 1981. A simple model for time-dependent stably stratified turbulent boundary layers. University of Washington Special Report No. 95.

Marino, R., And R. W. Howarth. 1993. Atmospheric oxygen exchange in the Hudson River: Dome measurements and comparison with other natural waters. Estuaries 16: 433445.

Moncrieff, J., R. Clement, J. Finnigan, and T. Meyers. 2004. Averaging, detrending, and filtering of eddy covariance time series, p. 7-31. In X. Lee, W. Massman and B. Law [eds.], Handbook of micrometeorology. A guide for surface flux measurement and analysis. Kluwer. 
Patankar, S. V. 1980. Numerical heat transfer and fluid flow. McGraw Hill.

Peaceman, D. W., and H. H. Rachford. 1955. The numerical solution of parabolic end elliptic differential equations. J. Soc. Indust. Appl. Math. 3: 28-41.

Rattray, M., and E. Mitsuda. 1974. Theoretical analysis of conditions in a salt wedge. Estuar. Coast. Mar. Sci. 2: 375-394.

Raupach, M. R. 1988. Canopy transport processes, p. 95-127. In W. L. Steffen and O. T. Denmead [eds.], Flow and transport in the natural environment: advances and applications. Springer.

Revsbech, N. P. 1989. An oxygen microelectrode with a guard cathode. Limnol. Oceanogr. 34: 474-478.

Schlichting, H. 1979. Boundary-layer theory, 7th ed. McGraw Hill.

Schmid, H. P. 2002. Footprint modeling for vegetation atmosphere exchange studies: A review and perspective. Agr. Forest Meteorol. 113: 159-183.

Schuepp, P. H., M. Y. Leclerc, J. I. Macpherson, and R. L. DesJardins. 1990. Footprint prediction of scalar fluxes from analytical solutions of the diffusion equation. Bound.-Lay. Meteorol. 50: 353-373.
STANIŠIĆ, M. M. 1985. The mathematical theory of turbulence. Springer-Verlag.

Stull, R. B. 1988. An introduction to boundary layer meteorology. Kluwer.

Swinbank, W. C. 1951. The measurements of vertical transfer of heat and water vapor by eddies in the lower atmosphere. J. Meteorol. 8: 135-145.

WiberG, P. L., And D. M. Rubin. 1989. Bed roughness produced by saltating sediment. J. Geophys. Res. 94: 5011-5016.

, AND J. D. Sмith. 1983. A comparison of field data and theoretical models for wave-current interactions at the bed on the continental shelf. Cont. Shelf Res. 2: 147-162.

— AND - 1991. Velocity distribution and bed roughness in high-gradient streams. Water Resour. Res. 27: 825-838.

WyngaARd, J. C. 1989. Scalar fluxes in the planetary boundary layer-theory, modeling, and measurement. Bound.-Lay. Meteorol. 50: 49-75.

Received: 7 March 2006 Accepted: 16 January 2007 Amended: 1 February 2007 